\title{
In Vitro Corneal Pathogenicity of Acanthamoeba
}

\author{
D. F. P. LARKIN, M. BERRY and D. L. EASTY \\ Bristol
}

\begin{abstract}
Summary
The comparative cytopathic effects of a keratitis and an environmental isolate of Acanthamoeba were studied on confluent monolayers of human and rabbit corneal cells grown in culture. The presence of cells in culture induced excystment of amoebae to the active trophozoite form. Total destruction of cell monolayers was observed to be similar for both isolates, and dependent on incubation time and amoebic concentration. The relevance of these findings to human and experimental Acanthamoeba keratitis is discussed.
\end{abstract}

Acanthamoeba is a genus of free-living amoebae which is ubiquitous in air, soil and aquatic environments. The active trophozoite form becomes a resilient cyst in unfavourable environmental conditions. Acanthamoeba is a cause of chronic granulomatous encephalitis, which occurs in immunocompromised hosts and is fatal. ${ }^{1}$ Certain species cause chronic stromal keratitis, particularly in contact lens wearers whose lens solutions become contaminated by the amoeba. ${ }^{2}$ The amoebae flourish in the corneal stroma, and a severe polymorphonuclear inflammatory response and corneal thinning is observed in both human ${ }^{3}$ and experimental ${ }^{4}$ keratitis.

In vitro studies of Acanthamoeba virulence have been performed on VERO cells ${ }^{5,6,7}$ a cell line derived from monkey kidney, or SIRC cells, ${ }^{8}$ derived from rabbit cornea. These studies equated the speed with which the mammalian cells were destroyed to virulence, and to pathogenicity in laboratory animals. ${ }^{6}$ Isolated rabbit corneas, used as an in vitro model for amoebic infection, demonstrated a similar destructive effect by known pathogenic and non-pathogenic strains of amoebae. ${ }^{8}$

Two questions have prompted this study.
The first was raised by Garner, who questioned whether the corneal thinning is caused by the inflammatory response or the amoebae themselves. ${ }^{3}$ Can Acanthamoeba feed on corneal cells? The second relates to the marked site-specificity of clinical Acanthamoeba infection: is corneal tissue unduly susceptible to amoebic infection?

To answer these questions we studied the interaction of Acanthamoeba and cell cultures. We first investigated whether Acanthamoeba excysts in the presence of cultured cells, and whether a cytopathic effect (CPE) results. We then conducted a comparative investigation of the effect of amoebic trophozoites on primary cultures of human and rabbit corneal cells, and on 3T3 alpha cells, a mouse fibroblast cell line. We contrasted the CPEs of Acanthamoeba spp. on these cells, and compared an environmental isolate with an isolate from an infected cornea.

\section{Materials and Methods}

1. Preparation of Acanthamoeba

Two strains of Acanthamoeba were used in these studies: an isolate from an infected cornea, $A$. polyphaga (Davies), and a soil isolate

From: Department of Ophthalmology, University of Bristol, Bristol Eye Hospital, Lower Maudlin Street, Bristol.

Correspondence to: Mr. D. F. P. Larkin, Moorfields Eye Hospital, City Road, London EC1V 2PD. 
of $A$. castellanii (Neff). The amoebae were kindly provided in axenic culture by $\mathrm{Mr}$. S. Kilvington, Public Health Laboratory, Bath. Each were cultured in axenic medium at $32^{\circ} \mathrm{C} .^{9}$ Flasks containing crowded amoebae were chilled at $0^{\circ} \mathrm{C}$ for two minutes to detach the adherent amoebae from the flask, and spun at $400 \mathrm{rpm}$ for five minutes. Amoebae were resuspended in either fresh axenic medium for maintenance in culture, or in tissue culture medium for experimental use.

\section{Preparation of cell cultures}

\section{(a) Rabbit corneal cells}

Eyes were obtained from four to seven months old rabbits. They were enucleated within one hour of death, and corneas were immediately cultured as follows.

After rinsing in sterile phosphate-buffered saline, the corneas were excised with a small margin of sclera. The endothelium and its basal membrane were peeled. Epithelium and a thin layer of stroma were dissected from the main bulk of posterior stroma as described by Stocker et al. ${ }^{10}$ Each layer was then separately treated. Small pieces $\left(<2 \mathrm{~mm}^{2}\right)$ were laid on the bottom of a $25 \mathrm{~cm}^{2}$ tissue culture flask, to which a small volume of culture medium was added 30 minutes later.

Eagle's minimum essential medium (MEM) (Gibco, Grand Island, New York) supplemented with $10 \%$ (v/v) fetal calf serum, penicillin, streptomycin, amphotericin B, and L-glutamine was used for both types of cells. Cholera toxin $(10 \mathrm{ng} / \mathrm{ml}$, Sigma Chemical Co., St Louis) was added to the epithelial cultures. Medium was changed twice weekly. Cells migrated out of explants and were grown to confluence, then split in the ratio 1:3 by trypsinisation. Cellular morphology and origin were the only criteria for labelling a culture 'epithelial' or 'stromal', and therefore we refer to them as 'corneal cells'.

\section{(b) Human corneal cells}

A corneo-scleral rim from a 19-year-old donor and a cornea unsuitable for transplantation from a six-year-old were used to generate human corneal monolayers. The corneas were dissected as described above and the explants were laid on collagenised flasks (Human placental collagen $20 \mu \mathrm{g} / \mathrm{cm}^{2}$, Sigma).
The culture medium, RPMI (Gibco), was supplemented with $10 \%$ (v/v) fetal calf serum, L-glutamine, insulin, hydrocortisone, epidermal growth factor and nerve growth factor (from Vipera lebetina venom, $10 \mathrm{ng} / \mathrm{ml}$, Sigma). The last two growth factors were added on alternate medium changes. Medium was changed twice weekly. Cultures were grown to confluence and then split in the ratio $1: 3$ by trypsinisation.

Monoclonal anti-corneal cytokeratin antibodies, AE1 and AE5 (ICN-Flow), which characterise corneal epithelial cells, and monoclonal anti-vimentin antibodies (ICNFlow) which stain intermediate filaments most common in mesoderm-derived tissues, were used to characterise the cultures. They were visualised by indirect fluorescence (FITC-linked anti-rat and anti-goat IgG respectively, ICN-Flow). We observed positive staining with all three antibodies, indicating a mixed population of epithelial and stromal cells: hence these were called 'corneal cells'.

\section{(c) $3 T 3$ alpha cells}

These cells, derived from mouse fibroblasts, were obtained from the European Collection of Animal Cell Cultures at the PHLS Centre for Applied Microbiology and Research, Porton Down, England.

\section{Measurement of neutral red absorption}

Neutral red accumulation was used to measure the number of live cells. ${ }^{11}$ Each cell culture plate included (i) control wells with culture medium but no amoebae, (ii) $A$. polyphaga and/or (iii) $A$. castellanii isolates.

Briefly, the cells were incubated with $50 \mu \mathrm{g} / 100 \mu \mathrm{l}$ neutral red for three hours, then rinsed with fresh medium. A brief fixation in formaldehyde $\mathrm{CaCl}_{2}$ was followed by destaining with $100 \mu$ l of $1 \%$ acetic acid in $50 \%$ ethanol for one hour, and read on an ELISA reader (Dynatech MR 5000) at $550 \mathrm{~nm}$.

\section{Inoculation of cysts on rabbit corneal cells} Rabbit corneal cells were seeded on a 24 well plate (Costar) at three concentrations: $10^{3}$, $10^{4}$, and $10^{5}$ cells/well in $200 \mu$ l aliquots. When the wells most densely seeded became confluent, $200 \mu \mathrm{l}$ of fresh MEM containing $A$. 
polyphaga cysts was inoculated in triplicate for each cell concentration on to the culture medium above the cell monolayer with a pipette, giving a final concentration of $5 \times 10^{2}$ and $5 \times 10^{4}$ cysts/well. At inoculation, care was taken not to traumatise the monolayer. Following incubation in humidified $\mathrm{CO}_{2}$ at 33$35^{\circ} \mathrm{C}$, observations of the morphology of the monolayer and amoebae were made 1,2 and 21 hours after inoculation, and daily thereafter for 12 days.

\section{Inoculation of trophozoites}

Confluent cell cultures were trypsinised and seeded on collagenised 96 well plates (Costar Ltd.) and again grown to confluence. A human isolate of $A$. polyphaga was used in each experiment; trophozoites were suspended in tissue culture medium and $100 \mu$ l aliquots pipetted into wells. The medium was not changed for at least 48 hours. Plates were incubated at $33-35^{\circ} \mathrm{C}$ in humidified $\mathrm{CO}_{2}$ for the duration of the experiments.

\section{(a) Rabbit corneal cells}

In three separate experiments, $A$. polyphaga trophozoites were suspended in $100 \mu \mathrm{l} \mathrm{MEM}$ and added to confluent rabbit corneal monolayers at the following concentrations: 0 (control), $10,10^{2}, 10^{3}, 10^{4}, 10^{5}$ and $10^{6}$ trophozoites/well. Observation commenced $1 \frac{1}{2}$ hours after introduction of trophozoites, continued hourly for the first six hours, and then daily for three or five days. At the end of the observation period, the relative numbers of surviving cells were quantified by neutral red absorption.

\section{(b) Human corneal cells}

In four experiments, $A$. polyphaga trophozoites were suspended in $100 \mu$ l of RPMI and added to confluent monolayers of human corneal cells at concentrations of $0,10^{2}, 10^{3}$ and $10^{4}$ trophozoites/well. Observations were made daily for three or five days. Neutral red absorption was measured at the end of each observation period.

\section{(c) Human corneal cells}

In four experiments, $A$. polyphaga trophozoites were suspended in $100 \mu \mathrm{l}$ of RPMI and added to confluent monolayers of human corneal cells at concentrations of $0,10^{2}, 10^{3}$ and $10^{4}$ trophozoites/well. Observations were made daily for three or five days. Neutral red absorption was measured at the end of each observation period.

(c) Human and rabbit corneal cell and $3 T 3$ alpha monolayers

Each type of cell was separately grown to confluence in RPMI medium and inoculated with $0,10,10^{2}$ and $10^{4}$ trophozoites/well.

Plates were inspected daily for four days, when a neutral red assay was performed.

6. A. polyphaga and A. castellanii inoculation

on human corneal cells

Confluent monolayers of human corneal cells were prepared on 96-well culture plates. Acanthamoeba isolates in suspension were added to separate culture plates. One hundred microlitres of amoebic suspension containing $10,10^{2}$ and $10^{4}$ trophozoites were added to each well. Plates were incubated for three days and observed daily. Neutral red absorbance was measured at the end of the observation period.

\section{Results}

Inoculation of cysts on rabbit corneal cells

The most densely seeded wells were covered

Table I. Excystment of Acanthamoeba polyphaga on rabbit corneal cells

\begin{tabular}{lcccc}
\hline $\begin{array}{l}\text { Monolayer } \\
\text { cysts/well }\end{array}$ & $\begin{array}{c}\text { Confluent } \\
5 \times 10^{2}\end{array}$ & $5 \times 10^{4}$ & $\begin{array}{c}\text { Not confluent } \\
5 \times 10^{2}\end{array}$ & $5 \times 10^{4}$ \\
\hline $1 \mathrm{~h}$ & few trophozoites & few trophozoites & n.c. & n.c. \\
$2 \mathrm{~h}$ & n.c. & small holes & n.c. & n.c. \\
$21 \mathrm{~h}$ & n.c. & big holes & n.c. & n.c. \\
10 days & n.c. & no corneal cells & n.c. & n.c. \\
12 days & intact monolayers & re-encystment & n.c. & n.c. \\
\hline
\end{tabular}

n.c. $=$ no observed change 
Table II. Cytopathic effect of Acanthamoeba trophozoites on rabbit corneal cells

\begin{tabular}{|c|c|c|c|c|c|c|}
\hline Exposure (hours) & 10 & $10^{2^{A m o t}}$ & $\begin{array}{c}10^{3} \\
\text { ebae/well }\end{array}$ & $10^{+}$ & $10^{5}$ & $10^{6}$ \\
\hline $\begin{array}{l}1 / \frac{1}{2} \\
21 / 2\end{array}$ & n.c. & $\begin{array}{c}\text { n.c. } \\
\text { amoebae }\end{array}$ & $\begin{array}{c}\text { small holes } \\
\text { amoebae }\end{array}$ & $\begin{array}{c}\text { amoebae } \\
\text { aggregates }\end{array}$ & $\begin{array}{c}\text { can see only } \\
\text { amoebae }\end{array}$ & $\begin{array}{c}\text { can see only } \\
\text { amoebae }\end{array}$ \\
\hline & n.c. & aggregates & aggregates & holes & n.c. & n.c. \\
\hline $\begin{array}{r}3^{1 / 2} \\
4\end{array}$ & n.c. & small holes & $\begin{array}{c}\text { round holes } \\
\text { small and }\end{array}$ & no cells & n.c. & n.c. \\
\hline $\begin{array}{r}6 \\
23\end{array}$ & $\begin{array}{l}\text { thinning } \\
\text { n.c. }\end{array}$ & $\begin{array}{l}\text { n.c. } \\
\text { n.c. }\end{array}$ & $\begin{array}{c}\text { large holes } \\
\text { n.c. } \\
\text { amoebae }\end{array}$ & rounding & $\begin{array}{l}\text { n.c. } \\
\text { n.c. }\end{array}$ & $\begin{array}{l}\text { n.c. } \\
\text { n.c. } \\
\text { cysts }\end{array}$ \\
\hline $\begin{array}{l}26 \\
30\end{array}$ & $\begin{array}{l}\text { n.c. } \\
\text { n.c. }\end{array}$ & $\begin{array}{l}\text { n.c. } \\
\text { thinning } \\
\text { holes in }\end{array}$ & $\begin{array}{c}\text { fronts } \\
\text { no cells }\end{array}$ & trophozoites & $\begin{array}{l}\text { n.c. } \\
\text { n.c. }\end{array}$ & only \\
\hline $\begin{array}{l}53 \\
72\end{array}$ & $\begin{array}{l}\text { n.c. } \\
\text { n.c. } \\
\text { thinning }\end{array}$ & $\begin{array}{c}\text { 9/12 wells } \\
\text { n.c. } \\
\text { n.c. }\end{array}$ & $\begin{array}{c}\text { n.c. } \\
\text { encystment }\end{array}$ & encystment & $\begin{array}{c}\text { n.c. } \\
\text { encystment }\end{array}$ & \\
\hline 120 & $\begin{array}{l}\text { intact monolayer } \\
\text { cysts }\end{array}$ & $\begin{array}{l}\text { some cells } \\
\text { trophozoites } \\
\text { cysts }\end{array}$ & & $\begin{array}{l}\text { no corneal } \\
\text { cells } \\
\text { encystment }\end{array}$ & & \\
\hline
\end{tabular}

n.c. $=$ no change

by a sometimes stratified layer of cells, while the rest of the wells presented only scattered cells. Within one hour of inoculation trophozoites were identified in the wells with confluent monolayers, but even after 21 hours there was no excystment in the remaining wells. The first CPEs were observed two hours after inoculation with $5 \times 10^{4}$ cysts, but not even at 21 hours with $5 \times 10^{2}$ amoebae. After 10 days, in the wells exposed to $5 \times 10^{2}$ cysts there were confluent monolayers, whilst at higher concentrations no corneal cells

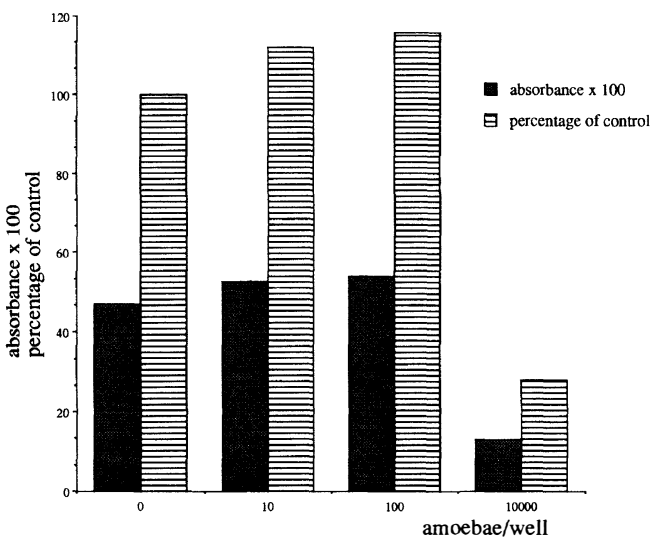

Fig. 1. Acanthamoeba trophozoites on rabbit corneal cells. Neutral red absorbance after 4 days of incubation with amoebae. Standard deviations (omitted) did not exceed $2 \%$ of mean $(n=12)$. could be seen and total re-encystment was noted [Table I].

\section{Inoculation of trophozoites}

(a) Rabbit corneal cells

All control wells, containing no amoebae, showed confluent healthy monolayers at the end of the observation period. In those wells inoculated with amoebae, trophozoites were observed to aggregate at the edges of cleared areas in the monolayer; as time elapsed, the area and number of discontinuities in the monolayer increased. Amoebae were also observed around areas of stratified corneal cells.

Results are summarised in Table II. Cytopathic effects were first observed at 26 hours in wells inoculated with $10^{2}$ amoebae, but at $1 \frac{1}{2}$ hours with trophozoite concentrations of $10^{3} /$ well or greater. Disappearance of corneal cells was not observed for concentrations less than $10^{3}$ trophozoites/well, but occurred within 26 hours in wells inoculated with $10^{3}$ trophozoites, and in three to six hours with $10^{4} /$ well. At higher concentrations, it was not possible to visualise the monolayer but total re-encystment was evident within two days at $10^{5} /$ well and 24 hours at $10^{6} /$ well. In wells containing 10 trophozoites no discontinuities appeared during the experiment. When only scattered cells remained in the wells, encyst- 


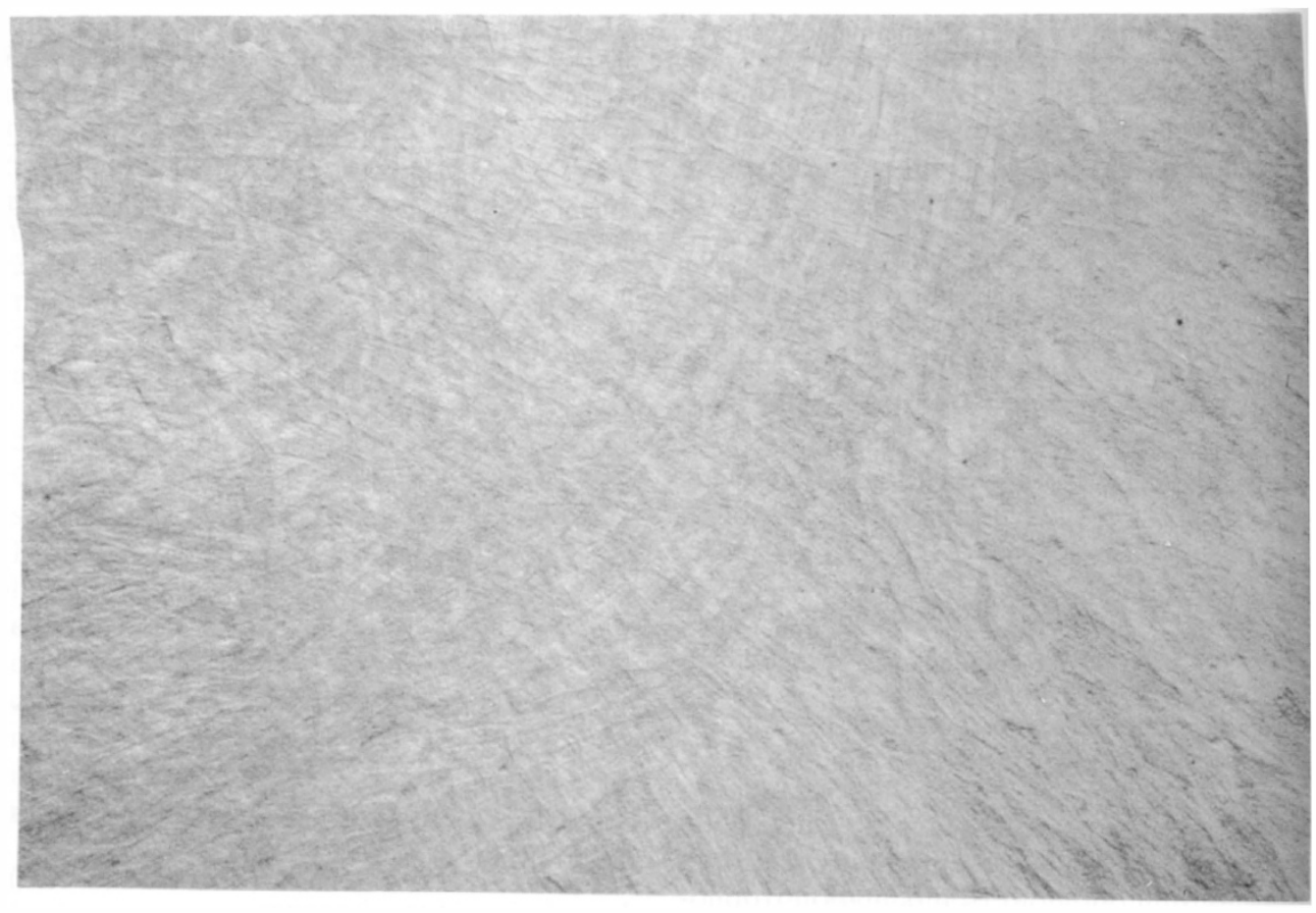

Fig. 2. Intact control monolayer of confluent human corneal cells at the end of the experiment $(\times 200)$.

ment of trophozoites was seen, initially to an immature single-walled cyst form. After four days of exposure, neutral red absorption in wells exposed to $10^{4}$ trophozoites/well was only a quarter of that of control (Fig. 1).

\section{(b) Human corneal cells}

Findings were similar to those observed with rabbit cells. Control wells showed no areas of discontinuity in the monolayer (Fig. 2). Trophozoites aggregated, were associated with zones of discontinuity in the monolayer (Fig. 3 ), and eventually re-encysted. Cytopathic effects were evident at 24 hours, and at $10^{4}$ trophozites/well, disappearance of corneal cells was seen after three days when neutral red absorbance reduced to $20 \%$ of control (Table III, Fig. 4).

(c) Human and rabbit corneal cell and $3 T 3$ alpha monolayers

Similar changes were observed on each of the cell types. Two days after inoculation, scattered trophozoites could be seen in the wells to which 10 amoebae had been added but no discontinuity in the monolayers was evident. At $10^{4}$ trophozoites/well, following disappearance of corneal cells from most wells by two days, re-encystment commenced. This was reflected in neutral red absorbance data (Fig. 5).

A. polyphaga and A. castellanii inoculation on human corneal cells

Monolayer cytopathic effects are shown in Table IV. After 24 hours there were areas of monolayer discontinuity in 10 of the 16 wells inoculated with $10^{4} \mathrm{~A}$. polyphaga trophozoites, and no corneal cells left in the other six wells. At the same concentrations of $A$. castellanii trophozoites, no corneal cells could be seen in any of the wells 24 hours after initial exposure. At lower concentrations of both species, no damage to the monolayer was identified.

\section{Discussion}

These studies demonstrate 


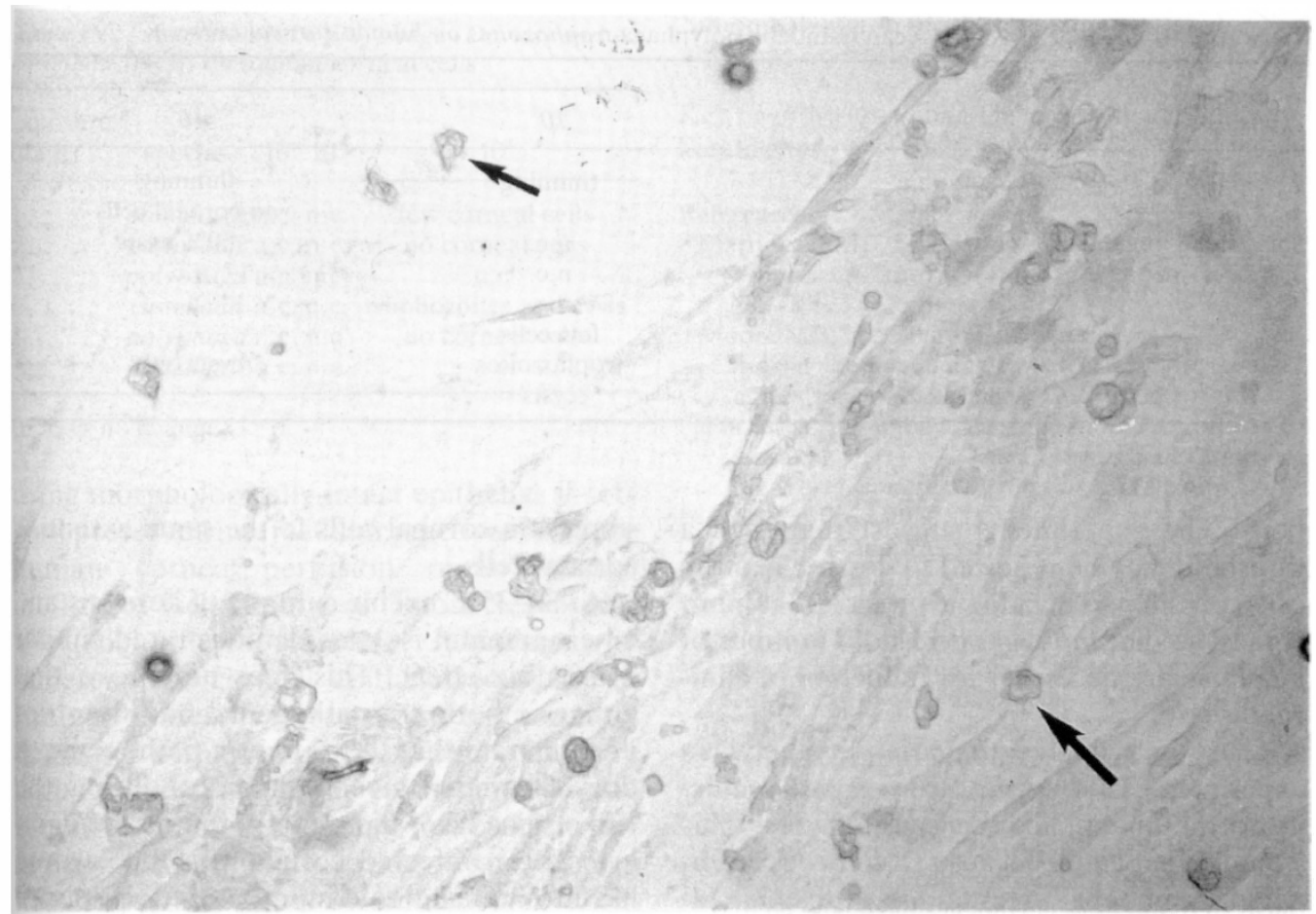

Fig. 3. Monolayer of human corneal cells photographed after 24 hours incubation with a keratitis isolate of A. polyphaga. Discontinuity in the corneal cell layer is seen on the left side. Trophozoites are seen in this area (small arrow) and in contact with corneal cells (large arrow) $(\times 200)$.

(i) that rabbit corneal cells in culture induce excystment of Acanthamoeba,

(ii) a cytopathic effect of Acanthamoeba on rabbit and human corneal cells in culture, dependent on incubation time and amoebic concentration;

(iii) equivalent cytopathic effects of human and environmental amoebic isolates.

The observation of amoebic excystment only on rabbit cell monolayers that were confluent suggests that the stimulus to excystment was present only if corneal cells were in excess. There is no apparent explanation for this finding. Disappearance of mammalian cells from the monolayer might be due to cell death induced by a soluble factor excreted by the amoebae, or mediated by amoeba-cell contact. Such a soluble protein has been described in Naegleria, another pathogenic genus of free-living amoeba. ${ }^{12}$ Furthermore, inhibition of Naegleria phagocytosis blocks the cytopathic effect on mammalian cells, a finding which favours contact mediation of kill. ${ }^{13}$ In the case of Acanthamoeba there is some evidence that cells are killed by contact ${ }^{8,14}$ Furthermore, $\mathrm{He}$ and colleagues have demonstrated collagenolytic activity of Acanthamoeba on purified collagen and rat corneas. $^{15}$

McLaughlin and colleagues observed amoebae aggregating at the junctions between corneal cells. ${ }^{8}$ In our experiments amoebae were consistently observed to be in the same plane as the cells. Aggregates of trophozoites were observed at the edges of zones free of cells. Accumulation of neutral red dye was observed in trophozoites inoculated on a neutral red-loaded monolayer. Though not sufficient proof that corneal cells are consumed by the amoebae, all the above findings support this hypothesis.

The data shown above indicate that there is a threshold concentration of Acanthamoeba necessary for induction of a cytopathic effect. We cannot specify whether this applies particularly to epithelial or stromal cells, or 
Table III. Cytopathic effects of Acanthamoeba polyphaga trophozoites on human corneal cells

\begin{tabular}{lccc}
\hline $\begin{array}{l}\text { Amoebae/well } \\
\text { exposure (days) }\end{array}$ & $10^{2}$ & $10^{3}$ & $10^{+}$ \\
\hline 1 & n.c. & thinning & thinning \\
& & & no corneal cells \\
3 & n.c. & n.c. & $\sim 50 \%$ cysts \\
4 & n.c. & n.c. & n.c. \\
5 & n.c. & n.c. & cysts only \\
\hline
\end{tabular}

n.c. $=$ no change

both. The experiments suggest that such a threshold may be required to destroy healthy cells, possibly to invade the intact epithelium. It may be that in vivo a threshold number of amoebae are necessary for induction of clinical disease.

There is a degree of variability between experiments of the time-scale of pathogenicity to the mammalian cell monolayers. This would be expected because virulence is attenuated in amoebae maintained in axenic culture medium, ${ }^{6.9}$ and not passaged through either an animal or a cell monolayer prior to experiments. However when different cells were exposed to the amoebae in the same experiment, the cytopathic effect was similar, irrespective of the monolayer origin. Demonstration of similar pathogenicity on corneal and fibroblast (3T3 alpha) cells indicates that, at least in vitro, Acanthamoeba can damage

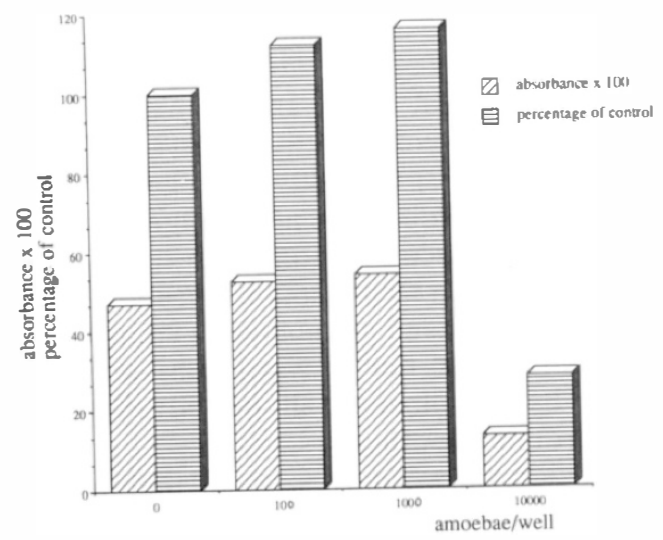

Fig. 4. Acanthamoeba trophozoites on human corneal cells. Neutral red absorption, as percentage of control, after 5 or 3 days of incubation with amoebae. some non-corneal cells. to the same extent as corneal cells.

At $32-35^{\circ} \mathrm{C}$ axenic cultures of keratitis and environmental isolates demonstrated similar cytopathic effect. This does not prove that either or both are pathogenic, and does not demonstrate that they are non-pathogenic: it does show that given similar conditions the two strains have the same potential for damage. In an infected cornea amoebae would have to induce tissue injury at a temperature close to that of the experiment. ${ }^{16}$

The monolayer of mixed epithelial and stromal cells described here has limitations in study of the interaction of Acanthamoeba and the epithelium. The human epithelial sheet culture system developed by Osato et al. ${ }^{17}$,

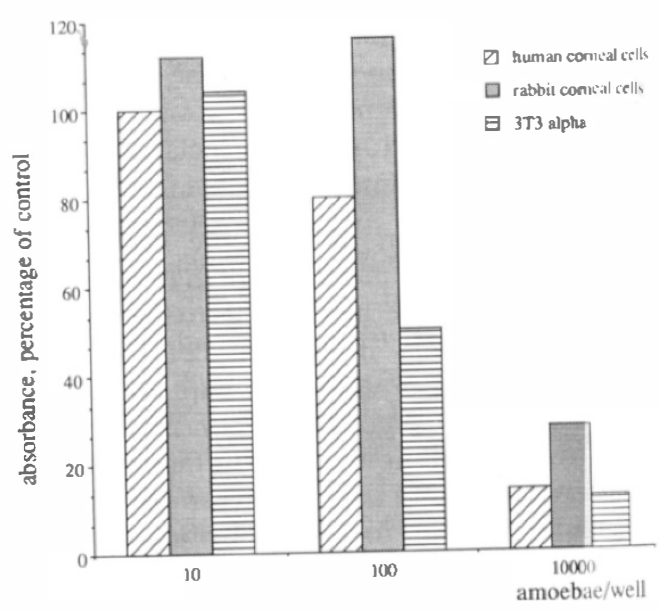

Fig. 5. Acanthamoeba trophozoites on human and rabbit corneal and $3 T 3$ alpha cells. Neutral red absorbance is shown as percentage of control, after days of incubation with amoebae. 
Table IV. Acanthamoeba polyphaga (Davies) and A. castellani (Neff) on human corneal cells

\begin{tabular}{|c|c|c|c|}
\hline $\begin{array}{l}\text { exposure } \\
\text { (days) }\end{array}$ & species & $1010^{2}$ & $10^{4}$ \\
\hline 1 & $\begin{array}{l}\text { polyphaga } \\
\text { castellanii }\end{array}$ & $\begin{array}{l}\text { n.c. n.c. } \\
\text { n.c. n.c. }\end{array}$ & $\begin{array}{l}\text { few corneal cells } \\
\text { no corneal cells }\end{array}$ \\
\hline 2 & $\begin{array}{l}\text { polyphaga } \\
\text { castellanii }\end{array}$ & $\begin{array}{l}\text { n.c. n.c. } \\
\text { n.c. n.c. }\end{array}$ & $\begin{array}{c}\text { n.c. } \\
\text { trophozoites and cysts }\end{array}$ \\
\hline 3 & $\begin{array}{l}\text { polyphaga } \\
\text { castellanii }\end{array}$ & $\begin{array}{l}\text { n.c. n.c. } \\
\text { n.c. n.c. }\end{array}$ & $\begin{array}{l}\text { no corneal cells } \\
\text { n.c. }\end{array}$ \\
\hline
\end{tabular}

(n.c. $=$ no change $)$

using morphologically intact epithelial sheets with preserved intercellular junctions, and the human cornea perfusion organ culture method of Tschumper et al. ${ }^{18}$ more clearly parallel the in vivo situation. Acanthamoeba adherence to corneal epithelial sheets, ${ }^{17}$ or contact lenses, ${ }^{19}$ increases with time and decreases with rinsing. Osato and colleagues argue that damage to the epithelium is a prerequisite for penetration: ${ }^{17}$ however in isolated cultured human corneas exposed to a high concentration of Acanthamoeba, abrading the epithelium did not significantly alter amoebic penetration. ${ }^{18}$ Whether amoebae enter an epithelial wound, or whether the trophozoites manage to infiltrate between cell junctions, ${ }^{8}$ only those that are not removed by tears or lid movements will be able to penetrate the stroma and induce disease.

In conclusion we would argue that Acanthamoeba keratitis is caused by opportunistic organisms infiltrating a cornea compromised in some respect. We further hypothesise that once a threshold number of trophozoites penetrate, subsequent inflammation occurs principally in the stroma rather than epithelium. This is probable because the stroma offers an environment more sheltered from ocular surface physical defences and host immunological defences, including for example, the avascularity and the known low number of antigen-presenting cells. ${ }^{20}$ This cell culture study is not a model for in vivo infection and one limitation is that it has not been possible to study whether the stromal cells themselves are more permissive than epithelial cells in sustaining amoebic activity and replication.

This study was funded in part by the National Eye Research Centre, Bristol. We are grateful to Mr.
Simon Kilvington for provision in axenic culture of amoebae.

Key words: Acanthamoeba, cytopathogenicity, keratocytes.

\section{References}

${ }^{1}$ Martinez AJ: Free-living amoebae: pathogenic aspects. A review. Protozool Abstr 1983, 7: 293-306.

${ }^{2}$ Moore MB, McCulley JP, Newton C, et al. Acanthamoeba keratitis associated with soft contact lenses. Am J Ophthalmol 1985, 100: 396-403.

${ }^{3}$ Garner A. Pathology of acanthamoebic infection. In Cavanagh HD ed. The Cornea: Transactions of the World Congress on the Cornea III. New York: Raven Press 1988: 535-9.

${ }^{4}$ Larkin DFP and Easty DL: Experimental Acanthamoeba keratitis. I. Preliminary findings. $\mathrm{Br} J$ Ophthalmol 1990, 74: 551-5.

${ }^{5}$ Visvesvara GS and Balamuth W: Comparative studies on related free-living amoebae with special reference to Acanthamoeba. J Protozool 1975, 22: $245-56$.

${ }^{6}$ Cursons RTM and Brown TJ: Use of cultures as an indicator of pathogenicity of free-living amoebae. J Clin Pathol 1978, 31: 1-11.

${ }^{7}$ De Jonckheere JF: Growth characteristics, cytopathic effect in cell culture, and virulence in mice of 36 type strains belonging to 19 different Acanthamoeba species. Appl Environ Microbiol 1980, 39: $681-5$.

${ }^{8}$ McLaughlin GL, Stimac JE, Luke JM et al.: Development of Acanthamoeba-cornea coincubation assays. Rev Inf Dis 1991, 13 (Suppl 5): S397-8.

${ }^{9}$ Neff RJ, Ray SA, Benton WF, Wilborn M: Induction of synchronous encystment (differentiation) in Acanthamoeba sp. Methods in Cell Physiol 1964, 1: 55-83.

${ }^{10}$ Stocker FW, Eiring A, Georgiade R, Georgiade N: A tissue culture technique for growing corneal epithelial, stromal and endothelial cells separately. Am J Ophthalmol 1958, 46 (suppl): 294-8.

${ }^{11}$ Borenfreund E and Puerner JA: Toxicity determined in vitro by morphological alterations and neutral red absorption. Toxicol Lett 1985, 24: 119-24.

${ }^{12}$ Dunnebacke TH and Dixon JS: NACM, a cytopathogen from Naegleria amoeba: purification, production of monoclonal antibody, and immunoreactive material in NACM-treated vertebrate cell cultures. J Cell Sci 1989, 93: 391-401.

${ }^{13}$ Brown T: Observations by immunofluorescence microscopy and electron microscopy on the cytopathogenicity of Naegleria fowleri in mouse embryo cell cultures. J Med Microbiol 1979, 12: 363-71.

${ }^{14}$ Stevens AR and O'Dell WD: In vitro growth of Acanthamoeba. J Parasitol 1974, 60: 884-5.

${ }^{15} \mathrm{He}$ Y, Niederkorn JY, McCulley JP, et al.: In vivo and in vitro collagenolytic activity of Acanthamoeba castellanii. Invest Ophthalmol Vis Sci 1990, 
31: $2235-40$.

${ }^{16}$ Efron N, Young G, Brennan NA: Ocular surface temperature. Curr Eye Res 1989, 8: 901-6.

${ }^{17}$ Osato MS, Pyron M, Elizondo M, et al.: Adherence and penetration of human corneal epithelium by Acanthamoeba. Invest Ophthalmol Vis Sci 1990, 31 (suppl): 420.

${ }^{18}$ Tschumper RC, Sloan LM, Rosenblatt JE, Johnson DH: A human in vitro model for Acanthamoeba keratitis. Invest Ophthalmol Vis Sci 1990, 31 (suppl): 419.

${ }^{19}$ Perkovich BT, Meisler DM, McMahon JT, Rutherford I: Acanthamoeba adherence to soft contact lenses. Invest Ophthalmol Vis Sci 1989, 30 (suppl): 198.

${ }^{20}$ Treseler PA, Foulks GN, Sanfilippo F: The expression of HLA antigens by cells in the human cornea. Am J Ophthalmol 1984, 98: 763-72. 